Article

\title{
Temperature-Dependent Analysis of Solid-State Photon-Enhanced Thermionic Emission Solar Energy Converter
}

\author{
Yang Yang ${ }^{1,2, *}$, Wei Wei Cao ${ }^{1,3,4}$, Peng Xu ${ }^{1,4}$, Bing Li Zhu ${ }^{1,5}$, Yong Lin Bai ${ }^{1,2}$, Bo Wang ${ }^{1}$, \\ Jun Jun Qin ${ }^{2,5}$ and Xiao Hong Bai ${ }^{2}$ \\ 1 Key Laboratory of Ultrafast Photoelectric Diagnostic Technology, Xi'an Institute of Optics and Precision \\ Mechanics, Chinese Academy of Sciences, Xi'an 710119, China; caoweiwei@opt.ac.cn (W.W.C.); \\ xupeng@opt.cn (P.X.); zhubingli@opt.ac.cn (B.L.Z.); baiyonglin@opt.ac.cn (Y.L.B.); wbo@opt.ac.cn (B.W.) \\ 2 State Key Laboratory of Transient Optics and Photonics, Xi' an Institute of Optics and Precision Mechanics, \\ Chinese Academy of Sciences, Xi'an 710119, China; qjj@opt.ac.cn (J.J.Q.); bxh@opt.ac.cn (X.H.B.) \\ 3 Key Laboratory for Physical Electronics and Devices of the Ministry of Education and Shaanxi Key \\ Laboratory of Information Photonic Technique, Xi'an Jiaotong University, Xi'an 710049, China \\ 4 University of Chinese Academy of Sciences, Beijing 100091, China \\ 5 Collaborative Innovation Center of Extreme Optics, Shanxi University, Taiyuan 030006, China \\ * Correspondence: yangyang@opt.cn
}

Received: 12 February 2020; Accepted: 20 March 2020; Published: 27 March 2020

check for updates

\begin{abstract}
Solid-state photon-enhanced thermionic emission (PETE) solar energy converters are newly proposed devices that can directly convert solar energy into electrical power at high temperatures. An analytical model based on a one-dimensional steady-state equation is developed to analyze the temperature-dependent performance of the solid-state PETE converter. The treatment used to derive the reverse saturation current density $\left(J_{0}\right)$ and open-circuit voltage $\left(V_{o c}\right)$ of the solid-state PETE converter is similar to that used in photovoltaic cells. Thus, their performances at elevated temperatures can be compared. Analysis results show that $J_{0}$ of the solid-state PETE converter with a GaAs absorption layer is approximately three orders of magnitude lower, and the decrease rate of open-circuit voltage $\left(-d V_{o c} / d T\right)$ is smaller than that of a practical GaAs photovoltaic cell. The improved performance of the solid-state PETE converter at high temperatures is attributed to the simultaneous use of diffusion and ballistic transport to harvest photo-generated electrons. The results presented in this paper demonstrate that, besides using wide bandgap materials and increasing doping density, harvesting solar energy via PETE effect can effectively improve the performance of solar cells at elevated temperatures.
\end{abstract}

Keywords: photon-enhanced thermionic emission; temperature dependence; solid-state device; solar cell; III-V semiconductors

\section{Introduction}

For concentrator photovoltaic systems and solar arrays of near-solar space probes, solar cells are generally exposed to high temperatures [1,2]. Unfortunately, the performance of solar cells degrades with the increase in temperature [3]. Efficiency degradation is primarily due to the decrease in open-circuit voltage $\left(V_{o c}\right)$ with the increase in temperature [1-5]. The reverse saturation current density $\left(J_{0}\right)$ is a critical parameter because it exponentially increases with increasing temperature and decreases $V_{o c}$ rapidly $[1,4] . J_{0}$ is a material-dependent parameter that relies on the bandgap and doping level of the material [4,5]. Wide bandgap solar cells, including photovoltaic cells made from GaInP [6], 
$\mathrm{GaP}$ [7], GaN [8], and SiC [9], were developed for high-temperature near-solar operations to improve the efficiency at high temperatures.

Recently, a novel high-temperature solar conversion concept called photon-enhanced thermionic emission (PETE) has been proposed, in which carrier separation is achieved by thermionic emission of photo-generated electrons from a hot cathode to a cold anode [10]. PETE can simultaneously utilize photon and thermal energy to achieve a conversion efficiency higher than $40 \%$ at a temperature of $200^{\circ} \mathrm{C}$. However, the vacuum gap that separates the cathode and anode results in numerous challenges in fabricating practical devices [11-13]. Diamond-based PETE cathodes with nanotexturing light receiving surfaces and hydrogenation emitting surfaces have been designed for high temperature operation $[14,15]$. A solid-state PETE solar energy converter has been proposed, to avoid the complicated fabrication and encapsulation of vacuum PETE devices [16]. The vacuum gap is replaced by a wide bandgap semiconductor layer. Carrier separation in the solid-state PETE converter is due to the internal PETE effect at the interface of the absorber and barrier layers, rather than the built-in electric field of a p-n junction in photovoltaic cells [17]. The conversion efficiency of the solid-state PETE converter exceeds $30 \%$ at a temperature of $600 \mathrm{~K}$ and a flux concentration of 1000 . However, the temperature dependence of parameters, such as $J_{0}$ and $V_{o c}$, and the performance of the solid-state PETE converter at elevated temperatures, need to be further studied in detail.

In this paper, an analytical model is proposed to investigate the temperature-dependent performance of the solid-state PETE converter. The critical parameters $J_{0}$ and $V_{o c}$ are derived on the basis of a one-dimensional steady-state continuity equation, which is a similar method for photovoltaic cells. We compare the temperature-dependent performance of the GaAs-based solid-state PETE converter and GaAs photovoltaic cells. Previous studies suggested that solar cells using wide bandgap and heavy doping materials would have better performance at high temperatures. The results presented in this study demonstrate that utilizing the PETE effect as a carrier separation mechanism is another effective method for reducing voltage degradation and improving the performance of solar cells at elevated temperatures.

\section{Materials and Methods}

In this study, for the single-junction photovoltaic cell and solid-state PETE converter, the effect of series resistance and shunt resistance is ignored, to simplify the problem. For a single-junction photovoltaic cell under steady state illumination, the current density-voltage $(J-V)$ characteristics can be described by solving the one-dimensional steady-state continuity equation [18]:

$$
J(V)=J_{p h}-J_{\text {dark }}(V)
$$

where $J_{p h}$ represents the photogenerated current density, and $J_{\text {dark }}$ is the junction current density without illumination, which can be described as follows [18]:

$$
J_{\text {dark }}(V)=J_{0}\left[\exp \left(q V / n k_{B} T\right)-1\right]
$$

where $J_{0}$ is the reverse saturation current density, $k_{B}$ is Boltzmann constant, $T$ is absolute temperature, and $n$ is the ideality factor. $J_{\text {dark }}$ is determined by several mechanisms. For high-quality materials, carrier recombination in the depletion region can be neglected. Thus, the ideality factor $n$ is close to unity $[4,5] . V_{o c}$ can be obtained from Equation (1) when $J=0$ [1]:

$$
V_{o c}=\frac{k_{B} T}{q} \ln \left(\frac{J_{s c}}{J_{0}}+1\right)
$$

where $J_{s c}$ is the short-circuit current density, and $J_{s c} \approx J_{p h}$. For simplicity, $J_{s c}$ can be described as follows [1]:

$$
J_{s c}=q \int_{E_{g}}^{\infty} \frac{I_{p h}}{d h v} d(h v)
$$


where $I_{p h}$ is the initial photon flux, and $E_{g}$ is the bandgap of the absorber material. $E_{g}$ decreases with the increase in temperature, which leads to a slight increase in $J_{s c}$ with increasing $T$.

For a single-junction photovoltaic cell, $J_{0}$ can be represented as follows [19]:

$$
J_{0}=q\left(\frac{D_{n}}{L_{n} N_{A}}+\frac{D_{p}}{L_{p} N_{D}}\right) n_{i}^{2}
$$

where $n_{i}$ is the intrinsic carrier density, and $D_{n}$ and $D_{p}$ are diffusion constants of minority carriers in $\mathrm{p}$ and $\mathrm{n}$ regions, respectively. $N_{A}$ and $N_{D}$ are the densities of the acceptor and donor, respectively. $L_{n}$ and $L_{p}$ respectively denote the diffusion lengths of minority carriers in $\mathrm{p}$ and $\mathrm{n}$ regions.

The solid-state PETE converter consists of a heavy doped p-type narrow bandgap semiconductor as the absorber, a wide bandgap semiconductor as the barrier, and metal electrodes. Figure 1 shows the band structure of the converter. From the perspective of thermionic emission, the absorber is treated as a cathode with a barrier of $V_{C}$, whereas the electrode is treated as an anode with a barrier of $V_{A}$. $E_{g 1}$ and $E_{g 2}$ are the bandgaps of the absorber and barrier layer, respectively. $S_{1}$ and $S_{2}$ are the interface recombination velocity at the front and emission interfaces, respectively. $d$ is the absorber thickness. The carriers are generated in the absorber and diffused to the hetero-junction interface. The conduction band offset $\left(\Delta E_{c}\right)$ at the interface is considerably smaller than the valence band offset $\left(\Delta E_{v}\right)$. In this condition, only photo-generated electrons can overcome the barrier by thermionic emission, whereas the transportation of photo-generated holes is blocked [20]. The barrier width is in the range of $10-100 \mathrm{~nm}$ to prevent electron diffusion and tunneling [21].

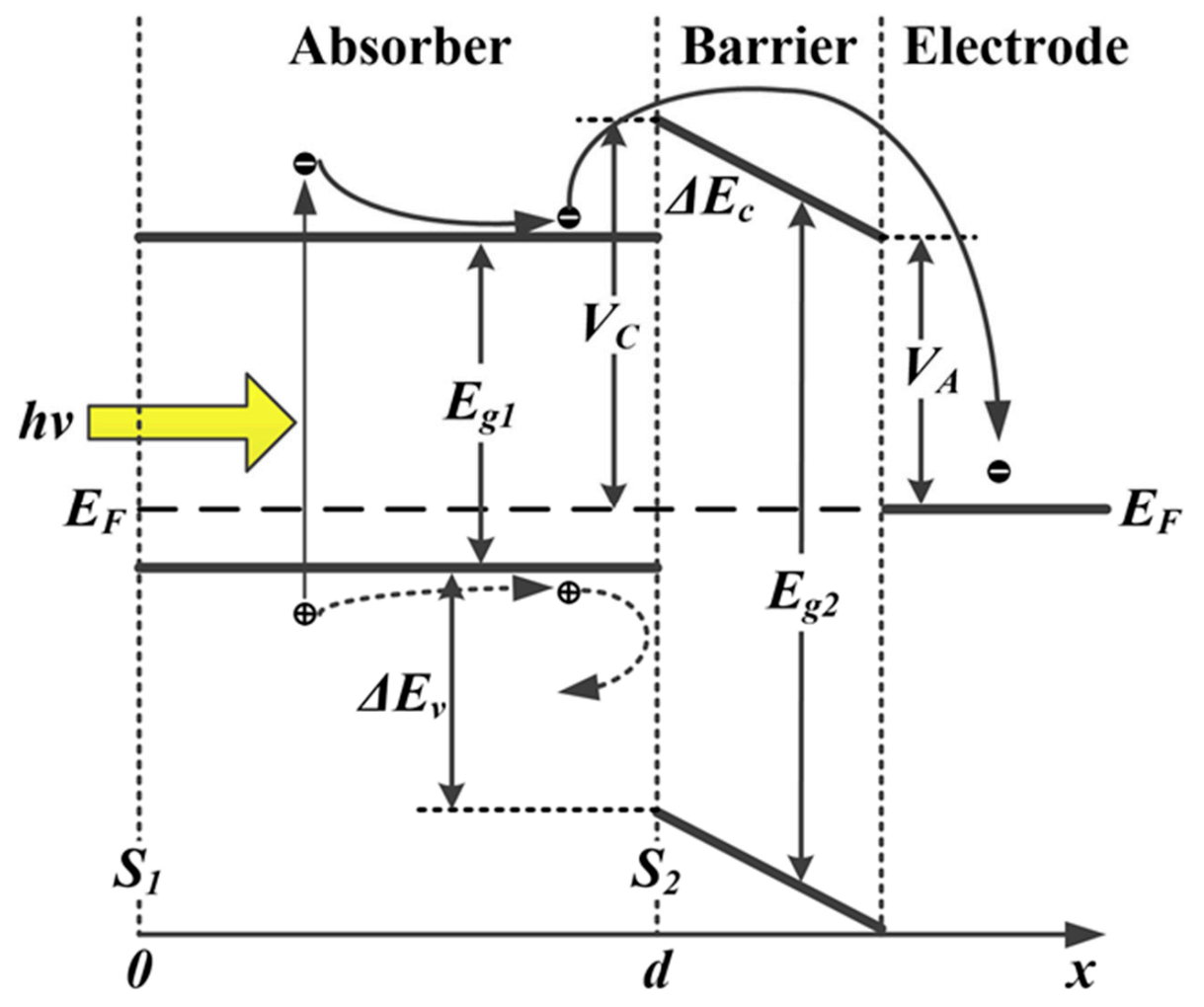

Figure 1. Band schematic of the solid-state photon-enhanced thermionic emission (PETE) converter.

The $J_{0}$ and $V_{o c}$ of the solid-state PETE converter are derived based on the one-dimensional steady-state continuity equation. We assume that the voltage difference is mainly across the barrier layer. Thus, the applied electron field inside the absorber is zero. The photo-generated carriers are 
assumed to support the local charge neutrality approximation. In the steady state, the continuity equation for photo-generated electrons is as follows [18]:

$$
\frac{d^{2} \Delta n(x)}{d x^{2}}-\frac{\Delta n(x)}{L_{n}^{2}}+\frac{G}{D_{n}}=0
$$

where $\Delta n$ is the concentration of photo-generated electrons, and $G$ is the photon generation function. The boundary conditions for excess electrons are as follows [17]:

$$
\begin{gathered}
\left.D_{n} \frac{d \Delta n(x)}{d x}\right|_{x=0}=\Delta n(0) S_{1} \\
-\left.q D_{n} \frac{d \Delta n(x)}{d x}\right|_{x=d}=q \Delta n(d) S_{2}+J_{e m}-J_{r e v}
\end{gathered}
$$

At the hetero-junction interface, the emission current from the absorber at a positive voltage $V$ is described as follows [22]:

$$
\begin{gathered}
J_{e m}=q n \sqrt{\frac{q k_{B} T}{2 \pi m_{n}}} \exp \left(-\frac{\Delta E_{c}}{k_{B} T}\right), \text { when } V \leq\left(V_{C}-V_{A}\right) / q . \\
J_{e m}=q n \sqrt{\frac{q k_{B} T}{2 \pi m_{n}}} \exp \left(-\frac{\Delta E_{c}+\left(V_{A}+q V-V_{C}\right)}{k_{B} T}\right), \text { when } V>\left(V_{C}-V_{A}\right) / q .
\end{gathered}
$$

Here, $n$ is the total conduction band concentration, and $m_{n}$ is the electron effective mass. The reverse current from the electrode to the absorber can be calculated as follows [22]:

$$
\begin{gathered}
J_{\text {rev }}=A T^{2} \exp \left(-\frac{V_{C}-q V}{k_{B} T}\right), \text { when } V \leq\left(V_{C}-V_{A}\right) / q . \\
J_{\text {rev }}=A T^{2} \exp \left(-\frac{V_{A}}{k_{B} T}\right), \text { when } V>\left(V_{C}-V_{A}\right) / q .
\end{gathered}
$$

Here, $A$ is Richardson's constant, and $120 \mathrm{~A} / \mathrm{cm}^{2} \mathrm{~K}^{2}$ is used in the calculation. The output current of the solid-state PETE converter is given as follows:

$$
J_{\text {SPETE }}=J_{e m}-J_{r e v}
$$

By solving the continuity equation with the boundary conditions derived above, the output current can be obtained. The output current of the solid-state PETE converter can be rewritten as Equation (1). When $G$ is set to zero, the dark current of the solid-state PETE converter is expressed as follows [23]:

$$
J_{\text {dark }}(V)=\frac{q D_{n} n_{e q}}{\beta L_{n}}\left[\exp \left(\frac{q V}{k_{B} T}\right)-1\right]
$$

where

$$
\begin{gathered}
\beta=\frac{q D_{n} N_{c}}{L_{n} A T^{2}} \exp \left(\frac{\Delta E_{c}}{k_{B} T}\right)+\frac{1}{a}\left[\cosh \left(\frac{d}{L_{n}}\right)+\frac{L_{n} S_{1}}{D_{n}} \sinh \left(\frac{d}{L_{n}}\right)\right] \\
a=\sinh \left(\frac{d}{L_{n}}\right)+\frac{L_{n} S_{1}}{D_{n}} \cosh \left(\frac{d}{L_{n}}\right)+\frac{b L_{n} S_{2}}{D_{n}} \\
b=\cosh \left(\frac{d}{L_{n}}\right)+\frac{L_{n} S_{1}}{D_{n}} \sinh \left(\frac{d}{L_{n}}\right) .
\end{gathered}
$$


A comparison of Equations (14) and (2) demonstrates that $J_{0}$ of the solid-state PETE converter differs from that of photovoltaic cells, as expressed by the following:

$$
J_{0}=\frac{q D_{n} n_{e q}}{\beta L_{n}} .
$$

The mechanism that determines $J_{s c}$ of the solid-state PETE converter is the same as that of photovoltaic cells. Hence, $J_{s c}$ of the solid-state PETE converter can be calculated using Equation (4), and $V_{o c}$ of the solid-state PETE converter can be calculated using Equations (3) and (15).

The conversion efficiency is computer as follows:

$$
\eta=\frac{J_{m} V_{m}}{P_{\text {solar }}}
$$

where $P_{\text {solar }}$ is the power received from the sun, and $J_{m}$ and $V_{m}$ are the optimum operating current and voltage, respectively.

\section{Results and Discussion}

In this study, GaAs with a doping density of $1 \times 10^{19} \mathrm{~cm}^{-3}$ was used as the absorber, and AlGaAs was used as the barrier layer in the solid-state PETE converter [17]. The model described above was implemented and solved numerically in MATLAB. For simplicity, diffusion lengths and diffusion coefficients were assumed to be temperature-independent in the simulation, following the same assumption as [11] and [24]. When simulating the performance of the solid-state PETE converter, the absorber thickness and conduction band offset took the optimal values. The surface recombination velocities of the front and emission interfaces were set to $10^{3} \mathrm{~cm} / \mathrm{s}$, which can be achieved in a high-quality heterostructure or a passivated surface $[25,26]$. For comparison, the temperature-dependent performance of a GaAs photovoltaic cell was also calculated. The temperature dependence curves of $J_{0}$ for the solid-state PETE converter and photovoltaic cell were obtained using Equations (14)-(15) and Equation (5), respectively. Combining Equations (3)-(5) and (15), the temperature dependence of $V_{o c}$ was calculated. The conversion efficiencies were obtained using Equation (16) under different temperatures and solar concentrations. For both the solid-state PETE converter and photovoltaic cells, the temperature dependence of the bandgap of GaAs was considered. The calculations used the AM1.5 global solar spectrum.

Figure 2 shows the temperature dependence curve of $J_{0}$ for the solid-state PETE converter with the GaAs absorption layer and GaAs photovoltaic cell with different doping concentrations. $J_{0}$ of all devices increased exponentially with the increase in temperature. The solid-state PETE converter achieved the minimum $J_{0}$ in the temperature range of 300-600 K. At the same temperature, $J_{0}$ of the photovoltaic cell with high doping concentration was small, which is consistent with the previous study [4]. This result is mainly due to the increase in doping concentration that causes a reduction in the equilibrium carrier concentration in the material, which is beneficial for reducing $J_{0}$ according to Equation (5). Figure 2 demonstrates that $J_{0}$ of the solid-state PETE converter was approximately one order of magnitude smaller than that of the GaAs photovoltaic cell with a doping density of $1 \times 10^{19} \mathrm{~cm}^{-3}$. Given that the absorption material of the solid-state PETE converter had the same band gap (GaAs) and doping density $\left(1 \times 10^{19} \mathrm{~cm}^{-3}\right)$, only the difference in their working mechanisms can explain the difference in $J_{0}$. In photovoltaic cells, the photo-generated carrier transport mainly involves diffusion. Thus, the expression of $J_{0}$ included only the diffusion parameters [1]. For the solid-state PETE converter, the carriers generated in the absorber diffused to the hetero-junction interface. Given that the barrier thickness was less than the mean free path of the carrier in the barrier material, photo-generated carriers traversed over the barrier by thermionic emission, which is a ballistic transport process [17]. The carrier separation and extraction in the solid-state PETE converter occurred via both diffusion 
and ballistic transport. Hence, its $J_{0}$ was determined by diffusion and thermal emission parameters, as shown in Equations (14) and (15).

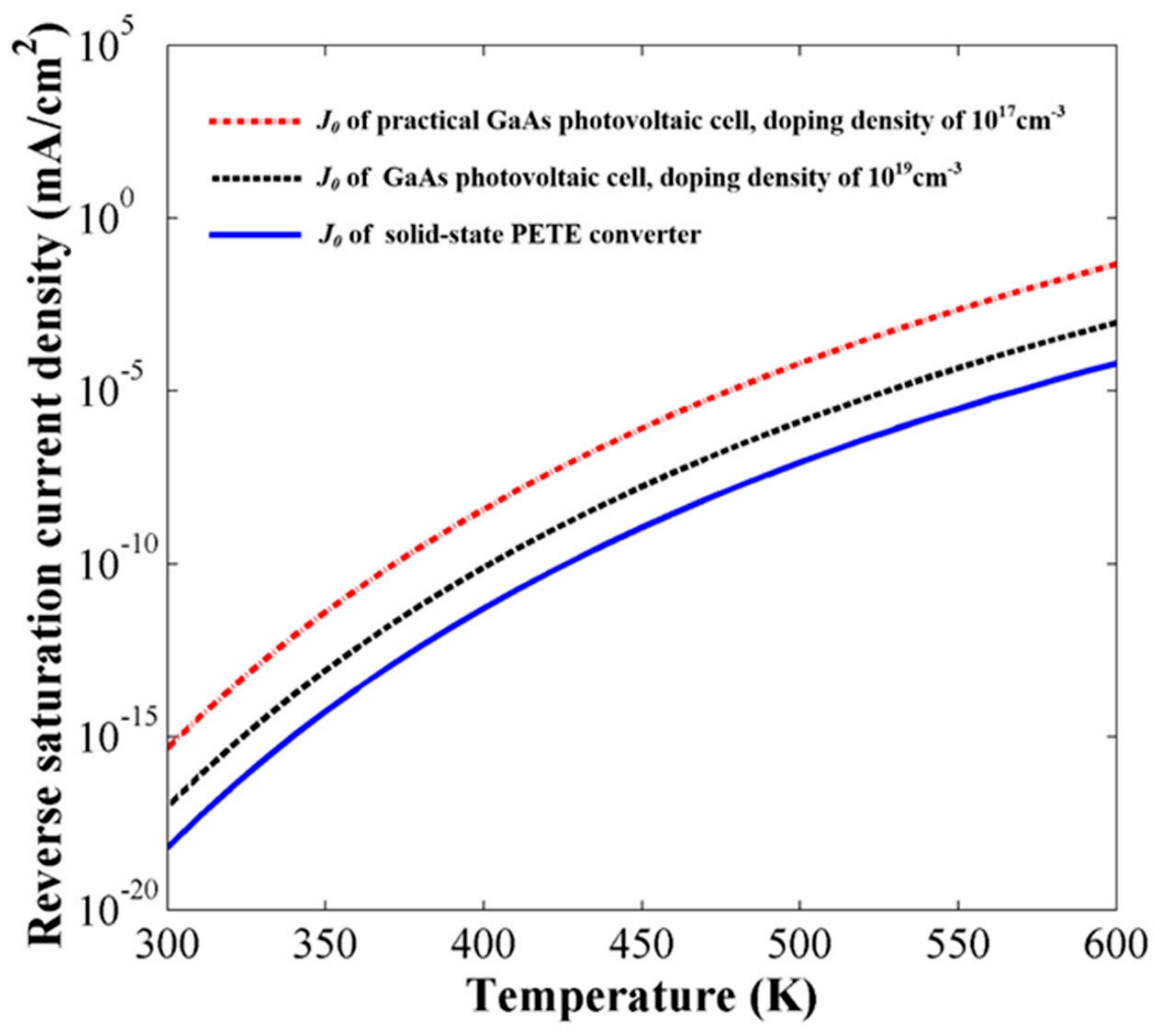

Figure 2. Temperature dependence of $J_{0}$ of the solid-state PETE converter with a GaAs absorption layer and GaAs photovoltaic cells with different doping concentrations.

Heavily doped semiconductor bulk materials are unsuitable to make $\mathrm{p}-\mathrm{n}$ homo-junction for practical photovoltaic cells. Carrier transport in photovoltaic cells mainly occurs through diffusion. With an increase in doping density, additional impurities and defects are introduced into semiconductor bulk materials, which leads to a decrease in carrier mobility, diffusion coefficient, minority carrier life, and diffusion length. These conditions affect the transport and collection of photo-generated carriers and reduce their efficiency [27-29]. Therefore, the doping density of practical photovoltaic cells is usually less than $1 \times 10^{18} \mathrm{~cm}^{-3}$. Increasing the doping density is ineffective in further improving the performance of photovoltaic cells at high temperatures. Compared with the practical GaAs photovoltaic cell with a doping density of $1 \times 10^{17} \mathrm{~cm}^{-3}[1,30], J_{0}$ of the solid-state PETE converter was approximately three orders of magnitude lower, as shown in Figure 2.

The temperature dependence of $V_{o c}$ is determined by $J_{0}$. For the device with low $J_{0}$, the decrease rate of $V_{o c}$ with temperature, that is, $-d V_{o c} / d T$, was small. Figure 3 shows $V_{o c}$ of the solid-state PETE converter with GaAs absorption layer and practical GaAs photovoltaic cell as a function of operating temperature under different flux concentrations (i.e., the concentration ratios of the incident solar radiation flux). At a flux concentration of 1 sun, $V_{o c}$ of the solid-state PETE converter decreased less with the increase in temperature, compared with that of practical GaAs photovoltaic cell, and $-d V_{o c} / d T$ of the solid-state PETE converter was approximately $70 \%$ that of the photovoltaic cell. Figure 3 shows that $V_{o c}$ of the solid-state PETE converter was higher than that of photovoltaic cells, which is due to the use of heavily doped material as absorber layer, which suppresses the equilibrium carrier concentration. 


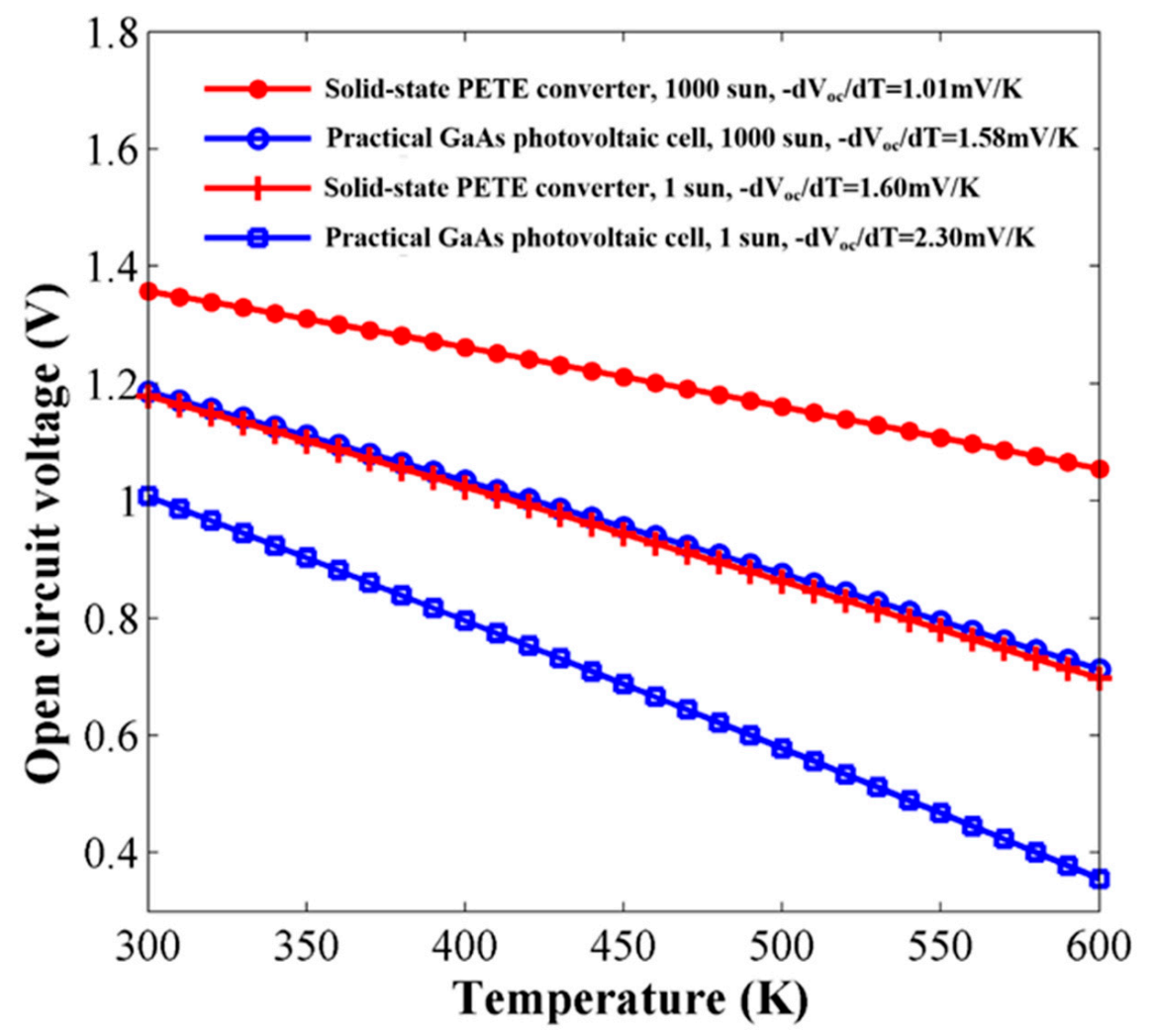

Figure 3. Variations in $V_{o c}$ with temperature for the solid-state PETE converter with GaAs absorption layer and practical $\mathrm{GaAs}$ photovoltaic cell under different flux concentration levels.

Increasing the irradiance concentration increased $V_{o c}$ and decreased $-d V_{o c} / d T$ for photovoltaic cells [31,32]. This trend was also valid for the solid-state PETE converter. Figure 3 shows that as the flux concentration increased from 1 sun to 1000 sun, $V_{o c}$ at a certain temperature increased, and $-d V_{o c} / d T$ decreased from $1.60 \mathrm{mV} / \mathrm{K}$ to $1.01 \mathrm{mV} / \mathrm{K}$. Notably, $V_{o c}$ and $-d V_{o c} / d T$ of the photovoltaic cell at 1000 sun were similar to those of the solid-state PETE converter at 1 sun. This result shows that by utilizing the novel conversion mechanism of PETE effect, the performance of solar energy converters can be effectively improved at high temperatures.

Since $J_{s c}$ increased slightly with increasing temperature, the degradation of conversion efficiency is mainly due to a decrease in $V_{o c}$. The conversion efficiencies of the solid-state PETE converter with GaAs absorption layer and practical GaAs photovoltaic cell as functions of temperature and incident solar radiation concentration are shown in Figure 4. The efficiency decreased as temperature increased, and increased as incident light intensity increased, which is consistent with the change trend of $V_{o c}$ with temperature and flux concentration. Under the same temperature and concentration conditions, the efficiency of the solid-state PETE converter with GaAs absorption layer was higher than that of GaAs photovoltaic cell. The conversion efficiency of the solid-state PETE converter was $28 \%$ at $600 \mathrm{~K}$ and a flux concentration of 1000 .

Solid-state PETE converters are suitable for working conditions under high temperatures and high light intensity. For concentrator solar systems, replacing photovoltaic cells with solid-state PETE converters can achieve increased efficiency. For concentrator hybrid systems combining solar cells and secondary thermal converters, solid-state PETE converters can function at high temperatures. Thus, additional heat energy can be delivered to the thermal cycle, boosting the total efficiency. For near-solar space missions, solar cells with improved performance at high temperatures are desirable over techniques, such as off-pointing array, increasing reflection, and active cooling, to reduce the temperature, but at the expense of losing total performance [2]. Harvesting solar energy via the PETE effect, combined with the use of wide bandgap and heavily doped materials, is a feasible strategy 
to achieve such high-temperature solar cells. Hetero-junction materials such as GaAs/AlGaAs and $\mathrm{Si} /$ diamond can be potential candidate materials.

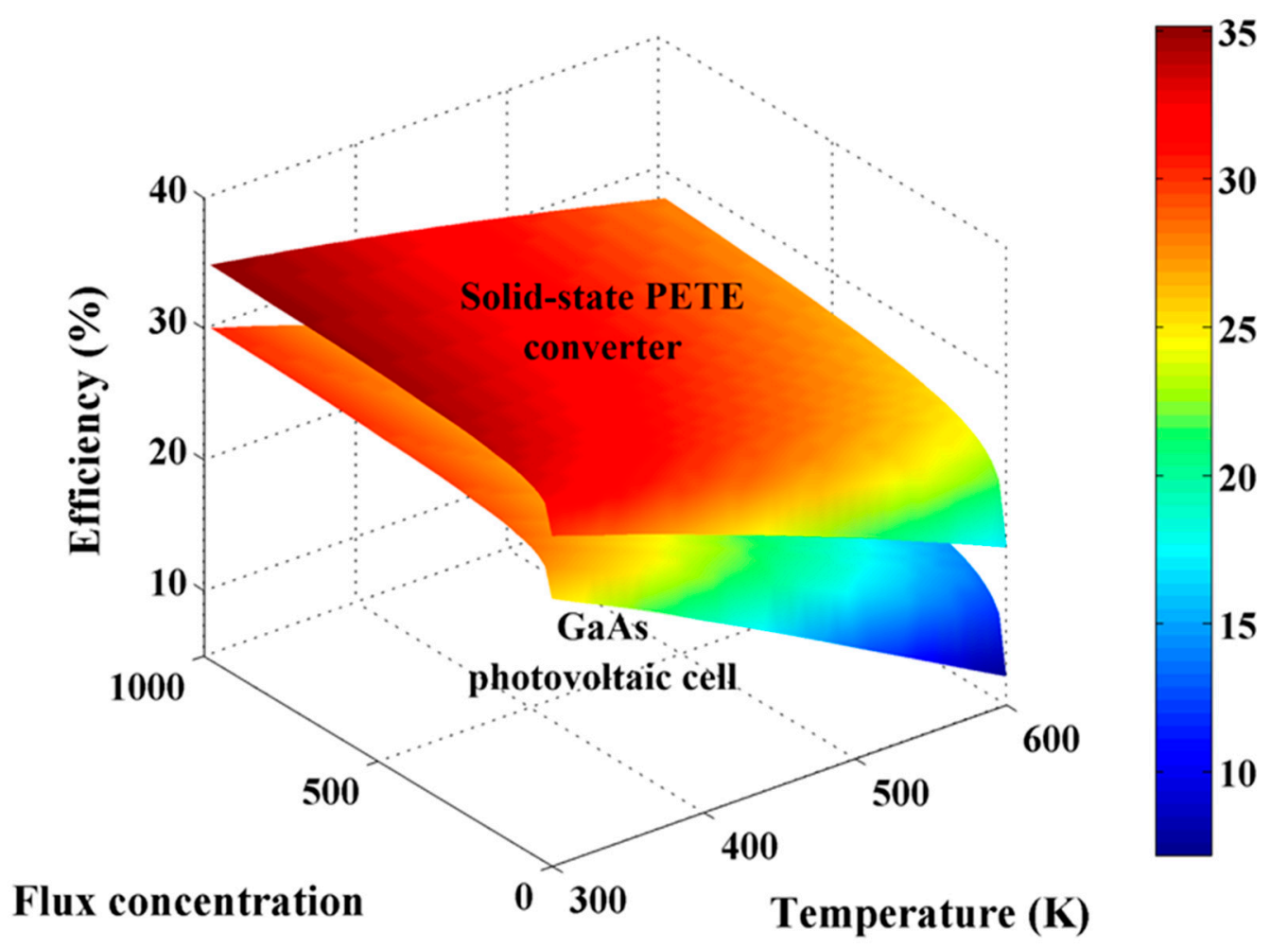

Figure 4. Efficiencies of the solid-state PETE converter with GaAs absorption layer and practical GaAs photovoltaic cell as functions of operating temperature and flux concentration of incident solar radiation.

\section{Conclusions}

An analytical model based on one-dimensional steady-state continuity equation is presented to investigate the temperature-dependent performance of the solid-state PETE solar energy converter. The treatment to derive $J_{0}$ and $V_{o c}$ of the solid-state PETE converter in this study is similar to that used in photovoltaic cells. The analysis results show that compared with the photovoltaic cells, the performance of the solid-state PETE converter at elevated temperatures is remarkably improved, due to its simultaneous use of diffusion and ballistic transport to harvest photo-generated electrons. $J_{0}$ of the solid-state PETE converter with GaAs absorption layer is approximately three orders of magnitude lower than that of the practical GaAs photovoltaic cell. At 1 sun, $-d V_{o c} / d T$ of the solid-state PETE converter is approximately $70 \%$ that of photovoltaic cell. As the flux concentration increases from 1 sun to 1000 sun, $V_{o c}$ of the solid-state PETE converter at a certain temperatures increases, and $-d V_{o c} / d T$ decreases from $1.60 \mathrm{mV} / \mathrm{K}$ to $1.01 \mathrm{mV} / \mathrm{K}$. The results presented in this paper show the feasibility of the solid-state PETE converter as a candidate device for concentrator solar systems and solar array of near-solar space probes to further improve their performances at high temperatures.

Author Contributions: Conceptualization: Y.Y. and W.W.C.; methodology: Y.Y. and P.X.; software: Y.Y. and P.X.; validation: W.W.C., P.X., and B.L.Z.; formal analysis: Y.Y. and W.W.C.; investigation: Y.Y.; resources: B.W.; data curation: Y.Y. and B.L.Z.; writing: Y.Y.; visualization: Y.Y. and P.X.; supervision: Y.L.B.; project administration: Y.Y. and Y.L.B.; funding acquisition: J.J.Q. and X.H.B. All authors have read and agreed to the published version of the manuscript.

Funding: This research was funded by the Equipment Pre-research Field Fund; grant number 6140721010203, and by West Light Foundation of Chinese Academy of Sciences; grant number XAB2016B25.

Conflicts of Interest: The authors declare no conflicts of interest. 


\section{References}

1. Singh, P.; Ravindra, N.M. Temperature dependence of solar cell performance-an analysis. Sol. Energy Mater. Sol. Cells 2012, 101, 36-45. [CrossRef]

2. Landis, G.; Rafaelle, R.; Merritt, D. High temperature solar cell development. In Proceedings of the 19th European Photovoltaic Science and Engineering Conference, Paris, France, 7-11 June 2004.

3. Green, M.A. General Temperature Dependence of Solar Cell Performance and Implications for Device Modelling. Prog. Photovolt. Res. Appl. 2003, 11, 333-340. [CrossRef]

4. Wysocki, J.J.; Rappaport, P. Effect of temperature on photovoltaic solar energy conversion. J. Appl. Phys. 1960, 31, 571-578. [CrossRef]

5. Fan, J.C.C. Theoretical temperature dependence of solar cell parameters. Sol. Cells 1986, 17, $309-315$. [CrossRef]

6. Geisz, J.F.; Steiner, M.A.; García, I.; Kurtz, S.R.; Friedman, D.J. Enhanced external radiative efficiency for 20.8\% efficient single-junction GaInP solar cells. Appl. Phys. Lett. 2013, 103, 041118. [CrossRef]

7. Sulima, O.V.; Sims, P.E.; Cox, J.A.; Mauk, M.G.; Mueller, R.L.; Reedy, R.C., Jr.; Khammadov, A.M.; Paulson, P.D.; Landis, G.A. High Temperature AlGaP/GaP Solar Cells for NASA Space Missions. In Proceedings of the 3rd World Conference on Photovoltaic Energy Conversion, Osaka, Japan, 11-18 May 2003.

8. Neufeld, C.J.; Toledo, N.G.; Cruz, S.C.; Iza, M.; DenBaars, S.P.; Mishra, U.K. High quantum efficiency InGaN/GaN solar cells with $2.95 \mathrm{eV}$ band gap. Appl. Phys. Lett. 2008, 93, 143502. [CrossRef]

9. Raffaelle, R.; Bailey, S.; Neudeck, P.; Okojie, R.; Schanabel, C.; Tabib-Azar, M.; Scheiman, D.; Jenkins, P.; Hubbard, S. Optical and Electrical Characterization of SiC Devices. In Proceedings of the 28th IEEE Photovoltaic Specialists Conference, Anchorage, AK, USA, 15-22 September 2000.

10. Schwede, J.W.; Bargatin, I.; Riley, D.C.; Hardin, B.E.; Rosenthal, S.J.; Sun, Y.; Schmitt, F.; Pianetta, P.; Howe, R.T.; Shen, Z.X.; et al. Photon-enhanced thermionic emission for solar concentrator systems. Nat. Mater. 2010, 9 , 762-767. [CrossRef]

11. Schwede, J.W.; Sarmiento, T.; Narasimhan, V.K.; Rosenthal, S.J.; Riley, D.C.; Schmitt, F.; Bargatin, I.; Sahasrabuddhe, K.; Howe, R.T.; Harris, J.S.; et al. Photon-enhanced thermionic emission from heterostructures with low interface recombination. Nat. Commun. 2013, 4, 1576. [CrossRef]

12. Kuriki, M.; Shonaka, C.; Lijima, H.; Kubo, D.; Okamoto, H.; Higaki, H.; Ito, K.; Tamamoto, M.; Konomi, T.; Okumi, S.; et al. Dark-lifetime degradation of GaAs photo-cathode at higher temperature. Nucl. Instrum. Methods Phys. Res. A 2011, 637, S87. [CrossRef]

13. Segev, G.; Weisman, D.; Rosenwaks, Y.; Kribus, A. Negative space charge effects in photon-enhanced thermionic emission solar converters. Appl. Phys. Lett. 2015, 107, 013908. [CrossRef]

14. Bellucci, A.; Calvani, P.; Girolami, M.; Trucch, D.M. Defect engineering of diamond cathodes for high temperature solar cells. In Proceedings of the IEEE 15th International Conference on Environment and Electrical Engineering, Rome, Italy, 10-12 June 2015.

15. Girolami, M.; Criante, L.; Fonzo, F.D.; Turco, S.L.; Mezzetti, A.; Notargiacomo, A.; Pea, M.; Bellucci, A.; Calvani, P.; Valentini, V.; et al. Graphite distributed electrodes for diamond-based photon-enhanced thermionic emission solar cells. Carbon 2017, 111, 48-53. [CrossRef]

16. Yang, Y.; Yang, W.; Tang, W.; Sun, C. High-temperature solar cell for concentrated solar power hybrid systems. Appl. Phys. Lett. 2013, 103, 083902. [CrossRef]

17. Yang, Y.; Yang, W.; Sun, C. Diffusion emission model for solid-state photon-enhanced thermionic emission solar energy converters. Mat. Sci. Semicon. Proc. 2015, 35, 120. [CrossRef]

18. Nelson, J. The Physics of Solar Cells; Imperial College Press: London, UK, 2003; pp. 112-170.

19. Hu, C.; White, R.M. Solar Cells; McGraw-Hill: New York, NY, USA, 1983; p. 21.

20. Avasthi, S.; McClain, W.E.; Man, G.; Kahn, A.; Schwartz, J.; Sturm, J.C. Hole-blocking titanium-oxide/silicon heterojunction and its application to photovoltaics. Appl. Phys. Lett. 2013, 102, 203901. [CrossRef]

21. Mahan, G.D.; Woods, L.M. Multilayer Thermionic Refrigeration. Phys. Rev. Lett. 1998, 80, 4016-4019. [CrossRef]

22. Segev, G.; Kribus, A.; Rosenwaks, Y. High performance isothermal photo-thermionic solar converters. Sol. Energy Mater. Sol. Cells 2013, 113, 114-123. [CrossRef]

23. Varpula, A.; Prunnila, M. Diffusion-emission theory of photon enhanced thermionic emission solar energy harvesters. J. Appl. Phys. 2012, 112, 044506. [CrossRef] 
24. Sahasrabuddhe, K.; Schwede, J.W.; Bargatin, I.; Jean, J.; Howe, R.T.; Shen, Z.X.; Melosh, N.A. A model for emission yield from planar photocathodes based on photon-enhanced thermionic emission or negative-electron-affinity photoemission. J. Appl. Phys. 2012, 112, 094907. [CrossRef]

25. Nelson, R.J.; Sobers, R.G. Interfacial recombination velocity in GaAlAs/GaAs heterostructures. Appl. Phys. Lett. 1978, 32, 761. [CrossRef]

26. Olson, J.M.; Ahrenkiel, R.K.; Dunlavy, D.J.; Keyes, B.; Kibbler, A.E. Ultralow recombination velocity at $\mathrm{Ga}_{0.5} \mathrm{In}_{0.5} \mathrm{P} / \mathrm{GaAs}$ hetero-interfaces. Appl. Phys. Lett. 1989, 55, 1208. [CrossRef]

27. Wolf, M. The influence of heavy doping effects on silicon solar cell performance. Sol. Cells 1986, 17, 53-63. [CrossRef]

28. Szmyd, D.M.; Hanna, M.C.; Majerfeld, A. Heavily doped GaAs: Se. II. Electron mobility. J. Appl. Phys. 1990, 68, 2376. [CrossRef]

29. Bergman, J.P.; Hallin, C.; Janzén, E. Temperature dependence of the minority carrier lifetime in GaAs/AlGaAs double heterostructures. J. Appl. Phys. 1995, 78, 4808. [CrossRef]

30. Loferski, J.J. Theoretical considerations governing the choice of the optimum semiconductor for photovoltaic solar energy conversion. J. Appl. Phys. 1956, 27, 777. [CrossRef]

31. Braun, A.; Katz, E.A.; Gordon, J.M. Basic aspects of the temperature coefficients of concentrator solar cell performance parameters. Prog. Photovolt. Res. Appl. 2013, 21, 1087-1094. [CrossRef]

32. Mesrane, A.; Mahrane, A.; Rahmoune, F.; Oulebsir, A. Analytical study on the temperature dependence of InGaN p-n junction solar cell under concentrated light intensity. Appl. Phys. A 2017, 123, 136. [CrossRef]

(C) 2020 by the authors. Licensee MDPI, Basel, Switzerland. This article is an open access article distributed under the terms and conditions of the Creative Commons Attribution (CC BY) license (http://creativecommons.org/licenses/by/4.0/). 